Crofton's paper discusses the situation in Scotland in general terms, giving a few examples of local initiatives and some general interpretations of the problems and the approaches to them. Campbell's paper provides an analysis of some of the ethical considerations starting from utilitarian and 'minimal state' theories, and contrasts them with what he considers to be a Christian view. It is, however, too brief to address the complexities of many of the issues adequately.

The reports from the discussion groups vary considerably in both depth and breadth, any may well not do justice to what took place. They range over topics including health education, pregnancy, and the roles of the private sector, voluntary agencies and the Church.

Overall, the book provides an introduction to inequalities in health but takes the issues little further forward. It may be helpful to those new to the field, but is unlikely to advance the thinking of those with prior knowledge.

K A HEWETSON

Department of Geriatric Medicine, East Birmingham Hospital,

Birmingham

\section{The Doctor as a Person}

Jan van Eys, John P McGovern, 151 pages, Springfield, Illinois, $\$ 26.50$, Charles C Thomas, 1988

Self-congratulation or self-examination? It is not clear at first sight exactly what the answer is to this question about The Doctor as a Person. It is a well produced book with some coloured illustrations, and it is based on the proceedings of the University of Texas M D Anderson Hospital and Tumor Institute at Houston's Eleventh Annual Mental Health Conference held May 22nd and 23rd, 1986 in Houston. There are contributions by twelve distinguished people, mostly teachers of medical specialities but they include a professor of ethics in medicine who has a doctorate in theology. The editors blithely believe that ultimately 'it is not the person who is shaped by the system ... the system is rather shaped by the person' ( $p$ xii). This idealistic outlook dominates the contributions. Hence, whilst occasional reference is made to the modern pressures on the medical profession, the social and structural determinants of behaviour are hardly examined. However, the contributions are interesting; indeed, some are quite moving such as the account by $\mathrm{Dr}$ Vanderwoude of his experiences as a cancer patient.

Essentially the writers explore what it means to be a professional man and a person, the relationship to patients and the cultivation of a caring attitude. Thus caring is helping the patient to cope with disease, whilst curing is removing it. Yet health, says Dr Van Eys is more than the absence of disease. It is possible to be healthy and have a chronic disease. To deny this, he says, is to 'consider ageing as unacceptable'. He makes the important point that the doctor does not stop at a biological cure for then there would be an uncured psychological cripple. Restoring health is healing which is described as "the gift to live on with memories of the disease, incorporated as a remembered but not devastating experience. To accept ourselves the way we are is the test of true health' ( $p$ 15). This means that the ideal physician is one who 'balances care of the patient with the application of knowledge and makes the whole more than the sum of the two' ( $p 24$ ).

Consideration of the doctor as a person leads some contributors to turn to particular problems in medical ethics; two may be mentioned. Firstly, the relationship of the medical scientist and the patient. Dr Frankel points to the differences between clinical and bench research, where the clinical researcher is also a carer and the needs of the patient must take precedence over research requirements. He goes on to discuss the nature and problems of 'informed consent'. Secondly, there is the problem of truth and deception, which is by no means as simple an issue as many believe. What to tell the patient and how to do so, especially when the physician is bearer of bad news are among the questions he deals with. Dr Lipscomb's essay on the subject is particularly useful where he argues against the place of deception in medicine and the dangers of paternalism. He examines the various permutations of the roles of doctor, nurse, patient, and family in relation to treatment in critical situations where the issue is to continue or discontinue treatment, and he makes some perceptive comments on various cases he has experienced.

Members of the medical fraternity are aware that the profession is not held in as high esteem as perhaps it has been, that litigation has increased, and that in the USA more than anywhere their high remuneration is envied. Self- congratulation is always hazardous and in this book there are signs that this is giving way to a growing awareness that all is not well. Self-examination on the part of the profession is obviously desirable for in some ways the physician has to play the role of God, and yet he has also to befriend his patient. The note of humility that is struck here by many of the contributors to this volume is surely a very good sign of health.

DUNCAN MITCHELL Emeritus Professor of the University of Exeter

\section{Acceptable Inequalities}

Edited by David Green, 64 pages, IEA Health Unit, £8.95, 1988

The topic of inequality in health care has been on the back burner since the public furore over the publication of the Black Report, Inequalities in Health: Report of a Research Working Group some eight years ago. Much of the public policy debate has been pushed aside by the concerns about general management and the new views of service quality and service delivery that now pervade the National Health Service (NHS). Acceptable Inequalities, a collection of four essays by Professors Klein, Pinker, Collison and Culyer is therefore a timely reminder of both an old question which has perhaps been forgotten in recent times, and also of the art of policy debate which has been little practised in recent times.

The four essays approach the notion of inequality in very different ways, reflecting the different intellectual backgrounds of the authors but all reach the conclusion that there will inevitably be inequalities in health and health care. In many ways, the essays provide traditional responses to the question: should inequality in health care be tolerated? The difficulties in the definition of terms such as equality and health, and the problems of reconciling differential end-states on health status with differential inputs of health resources all feature as prominent themes in the discussions. Few readers who have studied the debates over inequalities in health care which have taken place in the last decade will receive any intellectual shocks.

However, the essays are written against a background of the late 1980s rather than the late 1970 s, reflecting less concern for formulae dictating the structure of society and a greater 